\title{
Legal education in modern Russia: hermeneutic aspect
}

\author{
Alexey Ovchinnikov*, Anna Vakula, Tatyana Veselaya, Mikhail Smolensky \\ Don State Technical University, 34000 Rostov-on-Don, Russian Federation
}

\begin{abstract}
In order to comprehensively consider and then justify the need for the formation and development of professional and educational standards for training future professionals in the field of law, it is necessary to take into account many circumstances, the most important of which are: the positivist vector of the development of domestic jurisprudence; reforms of Higher Legal Education; reduction in hours in the study of historical and theoretical legal subjects, as well as humanitarian subjects in general. In the conditions of a technocratic state, the role of law in public life is increasing, which requires the recognition of the special importance of humanitarian subjects in the training of a professional lawyer, which needs the ability to sympathize, participate, be human, and respect human rights. Mass-producing of legal education results not only in the legal formalism of the legal bureaucratization of law enforcement agencies, caused by the loss of trust by the heads of state bodies to the moral and other qualities of the personnel who are forced to do everything according to the instructions, but also in the delegitimizing of rights, laws and bylaw acts, jurisprudence as a whole, which gradually turns into an instrument of a technocratic state.
\end{abstract}

\section{Introduction}

Even a superficial glance at the formation of modern professional and scientific legal thinking and sense of justice will note that something is wrong in legal education. Despite the dramatically increased opportunities to use modern technologies of access to the text of laws, as well as special legal literature, many graduates are still not capable of independent legal thinking and do not have a professional legal culture. The fact is that the modern education is moving further away from fundamental approaches to law to highly specialized ones.

Legal thinking and legal knowledge have different characteristics depending on the

\footnotetext{
* Corresponding author: vakulaann@,rambler.ru
} 
prevailing legal paradigm. In Russia there the positivist paradigm of legal thinking has long prevailed, which, however, does not make it stable: from time to time it is subjected to harsh criticism by some authors who note the gap between reality and simulacra of theoretical knowledge [1]. Regarding the criticism of the legal education system that emerged on its basis, we can also say: its extremely unsatisfactory state is well known $[2,3]$.

It is impossible to comprehensively consider all the causes and factors of such an order of things within the framework of this article. Let us pay attention to the connection between the methodology of perception of law, legal understanding and legal education. Russian lawyers rarely pay attention to this connection [4].

Training of a lawyer inevitably depends on the ethnic culture, national mentality, social and political situation - the fact is obvious. Lack of understanding of this situation obvious to any modern philosopher negatively affects the legal science and the legal education. This is due to the fact that the modern model of legal education does not imply a deep understanding of the meaning of law, which is possible only in the situation of active immersion in the legal sphere by expanding the context of interpretation of legal phenomena, and not by passively "reflecting" social and legal reality or memorizing imaginary laws. In real life, law does not exist in the form of an independent phenomenon that develops according to its own laws, as lawyers believed up to the present day and continue to believe because of the modernist worldview and methodology directive. In reality, human relations contain an inseparable tangle of legal, moral, political and religious values and aspirations. Law defies the only one dimension, the one single true definition, remaining elusive in an act of scientific rationality and reflection. Its insight is determined by the national and cultural semantic images that a person absorbs from an early age. Therefore, legal education, increasingly moving away from the philosophical and cultural context of law in the direction of legal positivism (the amount of humanitarian training, which a modern educational standard contains, is extremely insufficient) is moving away from the reality of human life, creating a virtual system of meanings of official law. Such an education forms a fragmented vision of the world and a "fragmented" perception of law in an infinitely diverse stream of life situations and human relations, unable to convey its unity, multidimensionality and harmonious integrity. This is especially facilitated by the specialization of legal education. A modern graduate of a law school has knowledge of the form, but not knowledge of the content: in this we can see the influence of logo-centrism and the "degenerated formal rationality" of European legal thinking, in which questions of justice have been replaced by questions of methods for its search.

\section{Results and discussion}

Let us turn to state standards. Whatever the reasons for the detachment of particular specialties "Legal national security protection" and "Law Enforcement", it is difficult to agree that they do not provide for the study of "Philosophy of law" and "History of Political and Legal doctrines". This violated three basic principles that the model of legal education in the XXI century should take into account: "expanding the context of perception of law", "understanding through application", "differentiating sense and meaning".

The first principle is associated with the introduction of a deep philosophical and cultural basis into legal education; the second follows from the unity of understanding and application noted in hermeneutics - in order to understand, in order to form the sense of a concept, text, social action, a person must practically "master " them, since only in this case will the mechanisms of understanding be involved; the third principle is 
related to the previous one - it should be remembered that the meaning and sense are different units of human communication and universal, the same for all perception of social and legal reality does not happen.

Italian scientist F. Gentile, fixing the growing belief in scientific circles that the training of lawyers has become more intense, and "at the same time they get much less knowledge", sees the reason in the increase of specialized legal knowledge, while it is much more important to master the basics and methods of studying different subjects, especially the philosophical basics of law [5]. The author believes that the lack of philosophy of law for lawyers, their passion for the analysis of laws instead of a deeper penetration into the legal principles serves as an obstacle to proper legal education, rightly noting that in everyday life in the legal experience logical form, economic interest and ethic value positions coexist.

It should be noted that similar trends are found in other areas of higher education. Foreign experts studying the state of education in Belgium, Denmark, France, and the Federal Republic of Germany believe that the crisis in the educational system is universal in nature, since "this is a crisis of the whole process, its development, its goals, student behavior" and is due to the fact that the world of education is actively penetrated by "the principles and innovations of the utilitarian technocratic world and, what is most dangerous, cynicism, superficiality, and transience of human contacts come into the world of pupils" [6]. According to domestic authors, modern university education around the world does practically nothing to form the ability "... to think independently and critically, i.e. reflectively and self-reflectively, creatively and contextually. As a result, thinking is defected: students are not able to use the acquired knowledge in practice. Or worse, they have not developed the ability to solve moral problems, interpersonal conflicts, social communication " [7].

However, in foreign jurisprudence over the past few decades, the works of formaldogmatic analysis of law has been forced into the background, giving way to the researches conducted at the intersection of law and other areas of humanitarian knowledge. This positively affects the legal training of students. Thys, for example, modern trends in the development of European education are connected with deep study of the history and sociology of law, as well as law in the socio-political context.

It should be recognized that today in Russia there is practically no own, distinctive and original philosophical and theoretical legal thought, the task of which would not be a blind imitation of Western models, but the search for its own path of legal development that meets the spirit and aspirations of the Russian people. Leading representatives of domestic jurisprudence, who quite rightly criticized the European bourgeois rule of law and capitalism as far from perfect socio-political ideals, proclaimed these models as dominants of state and legal development. Now, however, there is almost no doubt that these guidelines can lay claim to the universal role of moral and legal ideals for all mankind and supremacy in relation to other value orders.

At the same time, understanding of such a richest in its multidimensionality phenomenon as law, with the help of concepts developed in the Western European political and legal tradition, will be anything but science, since it is impossible to build a "general theory of law" from exclusively European experience history and cast aside the thousand-year experience of the other cultures' history, which does not fit into the Procrustean bed of ideas about the law of European science. Therefore, the most important term of science of law is overcoming European egocentrism and bringing into the orbit researches of all possible legal cultures.

Modern state-legal ideology, which has been fixed in the current Constitution of the Russian Federation, is a frank generalization of the ideals and norms of the liberal democratic version of the constitutional state and the European legal understanding as 
the only true and not subject to criticism of theoretical and methodological axioms. There are few studies that overcome frank Eurocentrism in the understanding of law and state and do not reproduce the cliches and stereotypes of the modernist era. The result is obvious: almost the entire country lives by the unwritten, "shadow law", by new, ugly forms of social justice, which the current legislation with its idealistic schemes is not able to provide.

Reforms in the field of professional education, "inspired" by plentiful consulting with foreign colleagues, especially from the United States, have led to the fact that the modern system of training legal staff for the law enforcement agencies of Russia is an artificial hybrid of the Soviet domestic educational system, which in the recent past was evaluated by the FBI director Hoover as "frighteningly effective," and the American system of police and other academies that meets the characteristics of the US legal and law enforcement system with its narrow specialization of uniformed and law enforcement agencies, which is completely different in relation to domestic, pre-trial procedural activities and other features of the Anglo-Saxon legal family. Why was it so hasty to give up their own experience in the field of education, including legal?

Legal thinking seems today to be a purely formal, rational and logical tool for managing and constructing social relations. With the help of such an "engineeringdesign" thought it is easy to construct an ideal society. From the point of such rationality it becomes clear why entire branches of legislation change so easily, the whole system of legal values and principles changes overnight. It does not take into account the fact that law, in the first place, is a product of culture, history, human life, and not of mind, engineering ingenuity and perception of law and, respectively, is a process of comprehension, not reflection. Therefore, legal science will be much more objective if its main task is to reveal the destinctive and unique structures of the legal existence of its people. It should be finally understood that the closer a lawyer to the legal life of his people is, the more he is "touched" by its unique legal culture, the closer to the real legal life and adequate his legal ideas, judgments, models will be. Legal thinking is not universal, it is "tied" to the law, to the legal values that the scientist absorbed since his childhood, like a sponge from the ocean: a variety of life situations, events and cases generated by the irrational human activity always remaining in the roots. No wonder that foreign lawyers, as well as numerous homegrown liberals and westerners, consider our legal culture to be outdated - a person raised in the "spirit" of protestant individualism and modern western materialism cannot understand that the main thing for a Russian person is not a "gift set" of his fundamental rights and liberties ("gift" in the sense "imposed from above"), but "Truth - Honesty", which cannot be reduced to formal legal equality and the "letter" of legal prescriptions.

The misunderstanding of this seemingly lying on the surface, existential observation generates the virtual reality of the scientific knowledge of law and the existence of the legislation itself: a striking proof of this is the theoretical construction of the "written" and "actual" Constitution of the Russian Federation, which is designed to "rescue" dogmatic constitutional and legal thinking from this virtual dead end.

However, with such a disparagement to philosophy in modern legal education, this is not surprising: the ideas of non-classical philosophy of the 20th century, primarily neoKantianism, existentialism, phenomenology and hermeneutics, focusing on the sociocultural foundations of the Humanities, apparently went unnoticed by the ideologists of reforms. The research efforts of Russian lawyers were either focused on the cultural and moral qualities of law. A strong tradition of domestic legal thought, which has always been a philosophical thought, and most of the Russian philosophers of the silver age were lawyers by training, is lost.

Against this background, it is extremely depressing to see the reduction of hours on 
the theory of state and law, philosophy, the exclusion of the history of political and legal doctrines from educational standards. After all, a lawyer, applying the General rule to a ызусшашс case, acts as a" co-author"," co-legislator", creatively overcoming the formality and abstraction of legal regulations, and here his human qualities, his legal intuition, knowledge of the peculiarities of the domestic political and legal culture and mentality, the identity of the Russian political and legal tradition and legal system are important. Sectoral subjects are undoubtedly the most important part of legal knowledge, but limiting the training of the future lawyers only to them is the same determination to educateстремление biorobots which role in legal life of society is limited by so-called "law enforcement syllogism". Let us not list numerous arguments refuting such an approach to law enforcement, let us only point out what any lawyer will agree with: when applying the rule, there is always an element of law-creating, and in most cases unconscious. Hence, the role played by the independent and "live" comprehension of the processes occurring in society by the applicant is already visible. His intellect, education, general humanitarian training, value-ideological position, general erudition play a crucial role in this process of expanding and supplementing existing law. After all, "the common basis of law is philosophy," as L. Giulio de la Morandiere, one of the largest lawyers of the 20th century, pointed out, also noting the particularly close connection of jurisprudence with the science of morality and sociology [7].

All these issues are solved by legal education. Only a thinking (understanding) person is able to adequately perceive and implement the regulatory text directed to him. First, it is necessary to teach a person to think, and then demand from him legal knowledge. Legislation is regularly updated, the content of regulations is changing, but the person with his worldview and thinking remains. The fact that domestic law has changed dramatically over the past decade indicates once again that for the activities of future lawyers, it is not the dynamic component of legal awareness (knowledge of positive (official) law) that is much more important, but the static one - an intuition of law and justice, a legal feeling, idea of law. The essence or the idea of law is comprehended not only by a rational, theoretical way, but by intuition, through the accumulation of political and legal experience, legal knowledge, ideas and views of other thinkers, primarily those who lived and thought in the framework of Russian history and culture. Therefore, the education of such intuition is not so much a matter of sectoral legal disciplines as historical and theoretical ones: philosophy and theory of law, history of political and legal doctrines, history of state and law, cultural studies, religious studies, etc.

It is important not to forget that professional intuition of law and justice, in its turn, is necessary for the teachers. Only a legally trained person has knowledge of the practical aspects of the law and the sectoral features of the implementation of its norms and, accordingly, can have direct legal experience. We therefore consider it perfectly fair that the philosophy of law should be lectured in the legal rather than the philosophical tradition. And the lecturer should be a highly educated lawyer, combining his legal experience with a deep philosophical and worldview analysis, using the achievements of modern philosophy, ethics and sociology.

G.J Berman gives an example: once Oliver Holmes told a class of law students: "This is your job as lawyers to see the connection between your specific fact and the mission of the entire universe." Behind this statement of Holmes, Berman believes, lies a tragic vision of the world generated by the civil war between the North and the South. "He knew how shaky the facts outside the General context are", - emphasizes the scientist [9]. Fragmentation and differentiation of the social sciences, a narrow view of law, which comes down only to the prevailing norms, procedures and techniques, deprives both lawyers, and representatives of other humanities - philosophers, political scientists, 
sociologists, from a rich source of understanding of their disciplines.

Thus, the current level of development of the social sciences, in general, and legal sciences in particular, requires new approaches to education. The longer the stereotypes and ideals of rationality prevailing over the last centuries of subject-object epistemology will extend to the principles of this sphere of human activity, the more time in the educational process will be wasted. Legal thinking will never be free from subjective structures of legal awareness and personal experience, which fundamentally changes the value of general humanitarian subjects in legal education. The thesis of the independence of legal awareness and respect for the law from the level of legal knowledge has not been innovative for a long time, which brings general humanitarian training to the first place in terms of importance.

In the Middle Ages, one of the peculiarities of the glossators school compared to modern legal education was that the meaning of educating in law was not seen in the study of modern medieval or Roman law, but in the training and upbringing highly educated legal scholars who are fluent in the methods of analysis and generalization and obtain philological abilities. At the same time, dispute was actively used as a form of training based on imitation of the court and application of the norm to a specific case. Educated at the University of Bologna, the specialists were distinguished by enviable analytical skills, which made them indispensable in the field of conflict. E. Anners notes that the first glossators immediately found themselves in the highest positions at the Imperial court, taking the positions of personal advisers to the Emperor[10].

Therefore, only if fundamental philosophical, philological, art history, cultural, sociological studies are involved in the orbit of legal education, is it possible to create an integrative legal understanding, which is increasingly discussed both in Russia and abroad. From "formal rationality" to the living law, from knowledge of procedures to knowledge of the fundamental basis of law, from form to content such a transition must occur in educational reform.

As one of the key tasks of social theory of law Berman, in addition to the integrating the three main areas of jurisprudence (legal positivism, natural law, historical school), considers the formation of such historical legal knowledge, which would be free from economic history (history of class struggle, etc.) and any other history. Law and its formation should be considered outside of cause-and-effect relations with respect to the other subjects of knowledge. The law of each country has its own unique history, due to the originality of the legal culture of the people - it seems that this is the way to interpret the judgment of the scientist who described in his voluminous study the way of formation and development of the western tradition of law in the context of sociocultural determinants. Religious, spiritual and practical factors are the basis of legal development of any civilization. In its turn, the law according to the G. J. Berman's approach played itself an important role in changing the periods of social and economic development of the West.

\section{Conclusions}

Now, when the question of the universality limits of humanitarian scientific knowledge becomes more acute, there can be no doubt that legal thinking should be "tied" to the ground on which one or another legal or political institution under study grows. Therefore, we believe that it is possible to raise the question of developing a united, basic, internally harmonious and synchronized block of social, humanitarian and legal subjects, which would include the history, philosophy, cultural studies of Russia, religious studies (history of Orthodoxy and other traditional confessions of our country), the history of the national state and law, the history of political and legal doctrines, the 
theory of state and law. This block should be studied for at least two years and be standard for training in any legal specialization, regardless of the university departmental affiliation. The fate of many people depends on the training of future law enforcement officers.

\section{References}

1. Legal hermeneutics in the 21st century (St. Petersburg, 2016)

2. I. M. Matskevich, Legal education and science. 4, 2-3 (2009)

3. Domnina A.V. Legal Education and Science. 1, 7-10 (2011)

4. Sinyukov V. N. Journal of Russian la", 7 (2009)

5. Gentile F. State and Law. 132-137 (1995)

6. Sulima I.I. Understanding approaches to the Humanization of Education: A study guide. (N. Novgorod, 1997)

7. N.S. Yulina, Questions of Philosophy, 2, 107 (1995)

8. J. de la Morandiere. Trans. from Fr., 29-30 (1958)

9. G. J. Berman, Western legal tradition: the age of formation (1994)

10. E. Anners History of European law (1994) 